\title{
Students' Vocabulary Knowledge: Comparative Study Enhancing Between Semantic Mapping and Diglot Weave Techniques
}

\author{
Olivia Virocky Simanjuntak and Debora Chaterin Simanjuntak \\ Universitas Advent Indonesia, Bandung Barat
}

\begin{abstract}
The purpose of this study is to find out whether there is any significant difference between Semantic Mapping and Diglot Weave Techniques in enhancing the students' vocabulary knowledge. This study is quantitative, utilizing comparative research design-a simple research design which is used to examine two techniques of teaching. In this study, the researcher treated two groups with two different techniques: Semantic Mapping and Diglot Weave. Each technique is deemed to be comparable in enhancing students' vocabulary knowledge. On the basis of the target this study, the researcher has to decide which technique that is more effective in enhancing students' vocabulary knowledge. The researcher found out that there is significant difference between group that was taught using Semantic Mapping technique and group that was taught using Diglot Weave Technique in enhancing students' vocabulary knowledge. In fact, the group that acquired Diglot Weave Technique had higher gain of score than the group that acquired Semantic Mapping.
\end{abstract}

Keyword - Semantic Mapping Technique, Diglot Weave Technique, Vocabulary Knowledge

\section{INTRODUCTION}

In order to learn English as a second language, learners should have well-established vocabulary knowledge. Having vocabulary knowledge is defined to have good comprehension of meanings. Alqahtani (2015) emphasized that knowledge of vocabulary is often viewed as a critical tool for language learners because a limited vocabulary knowledge may impede successful comprehension. Stæhr (cited in Hasan \& Shabdin, 2016) pointed out that vocabulary knowledge has become great contributor to language skills; it is comprehensively needed to discover learner's ability in learning his second language.

Nevertheless there are several difficulties that learners encounter in enhancing vocabulary knowledge. According to Shelby (2015), vocabulary is considered to be the most difficult aspect of English for foreign learners to master word meanings thoroughly. Other difficulties in learning vocabulary include fixed word collocation, phrasal verbs, idioms, proverbs and regional. As Puspita (2015) said in her study that most eleventh graders had difficulty to understand the text when they read analytical exposition texts due to insufficient vocabulary knowledge the learners had.

\section{Overview of the Study}

Keeping the above discussion, this study does rationale about comparing two techniques: Semantic Mapping and Diglot Weave to enhancing students' vocabulary knowledge. Semantic mapping strategy capitalizes on students' prior knowledge through the categorical arrangement of word concepts, affect substantially and positively general 
vocabulary knowledge. "Semantic mapping is a visual strategy for vocabulary expansion and extension of knowledge by displaying in categories words related to one another" (Kholi \& Sharififar, 2013). Nilforoushan (2102) stated in his study, "Semantic elaboration positively affects memory for (a) previously acquired words, (b) new words recorded as known words and (c) other types of stimuli (e.g. First language sentence recall)" (p, 165).

Meanwhile Diglot weave is related to code- mixing and code switching which are common and well-documented processes in the speech of multilingual individuals. According to Jingxia (cited in Nemati \& Maleki, 2013) "A common phenomenon in foreign language classrooms, code-switching between the target language and the first language is widely adopted by teachers in the process of teaching to build a bridge from known (the first language) to unknown (the target language)". (p. 1341). Moreover, Mehrabi (cited in Katemba \& Sitompul, 2018) entitled teaching vocabulary through Diglot Weave Technique that by using Diglot Weave technique, English teachers are able to utilize L2 as a meaningmaking tool for communicating ideas rather than an end in itself. It also reduces anxiety and enhances the affective environment for learning.

This study has aims after teaching vocabulary through Semantic Mapping (SM) and Diglot-Weave Technique (DWT) on vocabulary learning at SMA Perguruan Advent I Jakarta. The researcher conducted this study on students' vocabulary achievement of those who were taught by Semantic Mapping (SM) and those who were taught by Diglot Weave Technique (DWT); whether there is significant difference towards vocabulary enhancement between those who were taught using Semantic Mapping (SM) and those who were taught using Diglot Weave Technique (DWT), and students' response after being treated using Semantic Mapping (SM) and Diglot Weave Technique (DWT).

\section{LITERATURE REVIEW}

English learners cannot separate learning a new language from vocabulary because in learning a new language people have to know meaning of words used in the language. English learners cannot separate learning a new language from vocabulary because in learning a new language people have to know meaning of words used in the language. Richards and Renandya (cited in Rohmatillah 2014) emphasized that vocabulary is a core component of language proficiency because it provides basic knowledge of how speakers learn to speak, listen, read and write. Vocabulary is mostly known as a body of words used in a particular language, or in particular sphere, or at particular point of time (Lin, 2008). Nation (cited in Alfaki, 2015) stated that meaning encompasses the way that form and meaning work together, in other words, the concept and what items it refers to, and the associations that come to mind when people think about a specific word or expression.

However Weiser (2013) stated that limited vocabulary knowledge can negatively impact the development of student's reading comprehension skills because there is a strong relationship between vocabulary knowledge and reading comprehension since students need to comprehend meanings of critical words they will be reading. Therefore, English teachers should possess special skills in enhancing their learners' vocabulary knowledge. 


\section{Teaching Vocabulary}

Teaching vocabulary is quite challenging for English teachers because vocabulary is one of the most important part in learning language. Teachers are expected to know how ample meanings of words. According to Karakoça and Köseb (2017) Teaching vocabulary in second or foreign language is different from vocabulary learning in one's first language because the fact that the acquisition of second language needs more demanding process. Aside from that Timpson and Burgoyne (cited in Lynch \& Pappas 2017) suggested that teachers should be able to prepare their teaching by using warm-up exercises, assuming roles, as well as using props, in order to result good teaching. Altay (2017) said that there are several theories explain how human brain can access, store and manipulate lexical data. These three process seem to be not independent yet interactive because the process can trigger the others. When the problem is to understand lexicon of foreign language, the awareness to enable them to learn the words becomes stronger.

Therefore to help English learners obtain the process, numerous techniques to teach vocabulary should be considered-techniques that contain great elements to achieve particular indicators in enhancing learners' vocabulary knowledge. Hence, in this study, the researcher decided to compare two techniques: Diglot Weave and Semantic Mapping to enhance students' vocabulary knowledge. Both techniques have been utilized by many researchers to enhance learners' vocabulary knowledge.

\section{Semantic mapping Technique}

Semantic mapping consists of two essential words: semantic and mapping. Since semantic is a study of meaning in language, semantic mapping is considered as a technique adapted from theory of semantic to be one of teacher's strategies to teach vocabulary to the students. Semantic mapping is valuable instructional tools. Unlike many tools that just have one purpose, semantic mapping is flexible and endless in application (Harvey et al, 2000). Additionally Heimlich and Pittelman, (1986) explained that a Semantic Mapping is one type of graphic organizer; it helps students visually organize and graphically show the relationship between one piece of information and another. Thus semantic mapping is considered to be effective for readers who have low comprehension (Zarei and Adami (2013). Through the use of semantic mapping, teachers may benefit this technique in teaching vocabulary because English learners can create new context for students and learning would be more interesting. When students receive vocabulary instruction in semantic mapping, they can increase deeper knowledge of vocabulary which would help them use the vocabulary in appropriate situations (Nilforoushan, 2012).

Additionally, Harvey (2000) stated that is a valuable instructional tools; unlike many tools that have only one purpose, semantic mapping is flexible and possess endless application. Duffy (cited in Kasim and Wahyuni, 2016) said that Semantic Mapping is an effective technique to explain how to categorize word meanings to help learners distinguish one word from another. 


\section{Diglot Weave Technique}

The Diglot Weave, from the Greek 'di', meaning 'two', and 'glot', meaning 'language', is a breakthrough in language learning. Diglot weave is related to code- mixing and code switching which are common and well-documented processes in the speech of multilingual individuals. Syres and Scotton (cited in Fitria, 2014) said that code-switching is the use of two language varieties in the same conversation.

Among these, the Diglot Weave technique can be extremely useful way of employing students' first language (L1) to emphasize important concepts, reacquire the students' attention when they become distracted, and to praise and reprimand as required (Cook, 2001). Additionally, Bradley (2003) added that the use of first language in the classroom will gradually phase out as learners try to be more proficient in their second language because code-switching is involved to supply vocabulary items which they are familiar with.

According to Leon (cited in Sitompul, 2017) the term Diglot Weave was coined. It is actually a technique for teaching a second language or a foreign language. This technique smoothly weaves the new language into the learners' minds, taking them from the familiar to the unfamiliar. Gradually moving from their own language to the target language quickly builds comprehension skills and increases confidence.

\section{METHODOLOGY}

This is a comparative study which involves two groups. Each group was treated in different techniques. One group was treated using Semantic Mapping Technique the other group was treated using Diglot Weave Technique. The two groups were given pre-test and post-test. The pre-test was given in the beginning of the study to know the ability of the respondent before having treatment from the researchers and the post-test in the last meeting of the study to know the improvement with the pre-test result. The researchers also distributed questionnaire to find out students' response toward the given treatment.

The population of this study is high school students in Central Jakarta and the sample were students from grade X from SMA Perguruan Advent I Jakarta. In conducting the research, the researchers utilized the procedure of Semantic Mapping from Denton, et al (2007) while the procedure of Diglot Weave Technique is adopted from Dickinson and Tabors; Storch and Whitehurst cited in Sitompul (2017).

The instrument used in this study is a test to indicate students' vocabulary knowledge. Another instrument used in this study is a questionnaire; the purpose of distributing questionnaire to the students is to find out students' responses towards learning techniques that are given in enhancing their vocabulary knowledge.

Data obtained from the study were analyzed using statistical formulas. This is done to determine whether there is significant difference between the two techniques used. 


\section{RESULTS AND DISCUSSION}

In order to find out vocabulary achievement between two groups, as they were treated using different techniques: Semantic Mapping and Diglot Weave. The researcher did calculation based on the result of Pre-test, Post-test to get the Normalized Gain and Standard Deviation of the two groups after being treated. As seen on the table below, both groups have equal knowledge of vocabulary before being treated with the techniques - the mean score of the group that was treated using Diglot Weave was 68.19 while the mean score of the group that was treated using Semantic Mapping was 69.5. After each group was treated, the group that was treated using Diglot Weave Technique has significant increase in the mean score of the Post-test; it is 82.19; while the mean score of the group that was treated using Semantic Mapping is 77. It is a good consideration if the standard deviation is lesser. As seen in the table, the standard deviation of Diglot Weave is lower than Semantic Mapping.

Table 1: Pre-Test, Post Test, Standard Deviation and Normalized Gain

\begin{tabular}{|l|c|c|c|c|}
\hline \multirow{2}{*}{} & \multicolumn{2}{|c|}{ DWT } & \multicolumn{2}{c|}{ SM } \\
\cline { 2 - 5 } & Mean & St. Deviation & Mean & St. Deviation \\
\hline Pre-test & 68.19 & 10.428 & 69.5 & 10.52 \\
\hline Post-test & 82.19 & 9 & 77 & 8.596 \\
\hline $\begin{array}{l}\text { Normalized } \\
\text { Gain }\end{array}$ & 0.44 & 0.119 & 0.245 & 0.099 \\
\hline
\end{tabular}

\section{Normality Test of Pre-Test}

In comparative study, the researcher should be aware that both groups should have the same ability in vocabulary knowledge. Therefore normality test of Pre-test was conducted.

\section{Table 2 : Normality test}

\begin{tabular}{|l|l|c|c|c|}
\hline \multicolumn{2}{|c|}{ Group } & \multicolumn{3}{c|}{ Shapiro-Wilk } \\
\cline { 3 - 5 } \multicolumn{2}{|c|}{} & Statistic & df & Sig. \\
\hline \multirow{2}{*}{ Pretest } & DWT &, 956 & 21 &, 434 \\
\cline { 2 - 5 } & SM &, 945 & 20 &, 303 \\
\hline
\end{tabular}

Based on the data above, it depicted that the populations' score of both groups were normally distributed; because the significant value of Diglot Weave Technique is 0.434 which is greater than $\alpha(0.05)$ and Semantic Mapping is 0.303 which is greater than $\alpha(0.05)$. After conducting normality test of the Pre-test, Homogeneity Test was conducted to find out whether the two groups were homogeneous. 
Table 3: Homogeneity Test of Pre-Test

\begin{tabular}{|c|c|c|c|}
\hline Levene Statistic & df1 & df2 & Sig. \\
\hline, 049 & 1 & 39 &, 826 \\
\hline
\end{tabular}

The result above presented that the significant value is 0.826 which is greater than $\alpha$ (0.05). The results show that the population variances between those who acquired Diglot Weave and Semantic Mapping were homogeneous.

\section{The Result of Independent Sample t-Test of Pre-Test}

Independent sample t-test was done to find out the row for equal variances assumed because the population variances should be homogeneous.

Table 4: Result of Independent sample t-test of pre-test

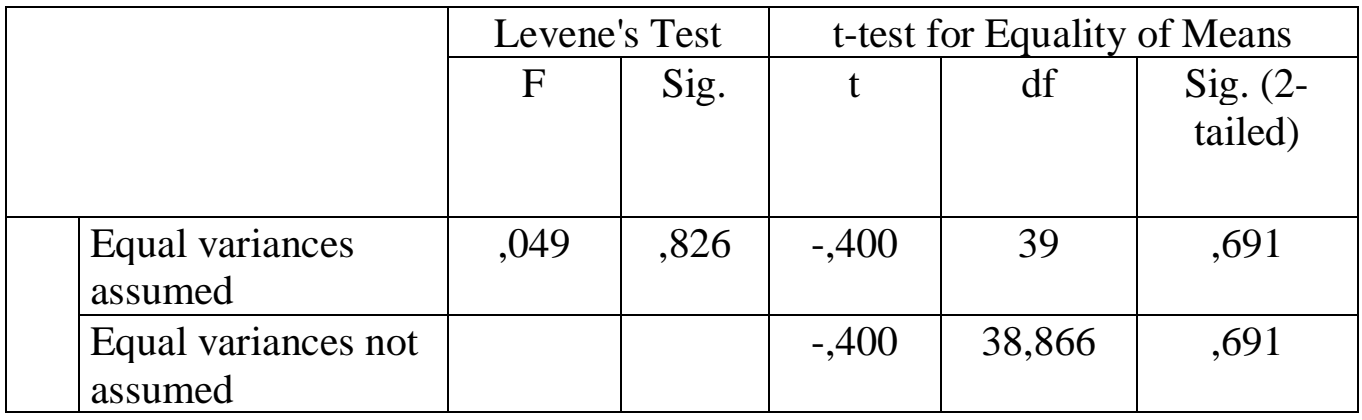

Based on the result above, the $\rho$-value of the pre-test score is 0.691 which is greater than $\alpha(0.05)$, it means that $\mathrm{H}_{0}$ is accepted which means there is no significant difference between pre-test scores in both groups. Conclusively, the two groups were comparable.

In seeking the answer whether Diglot Weave and Semantic Mapping have significant difference. The researcher conducted Normality Test of Gain Score.

Table 5: Normality Test of Gain Score

\begin{tabular}{|l|c|c|c|c|}
\hline \multicolumn{2}{|c|}{ Group } & \multicolumn{3}{c|}{ Shapiro-Wilk } \\
\cline { 2 - 5 } & Statistic & df & Sig. \\
\hline Gain & SM &, 969 & 21 &, 702 \\
\cline { 2 - 5 } Score & DWT &, 954 & 20 &, 427 \\
\hline
\end{tabular}

Based on the data table above, both data was normally distributed because the significant value of the gain score for Sematic Mapping group is 0.702 which is greater than $\alpha(0.05)$ and the significant of the gain score for Diglot Weave group is 0.427 which is greater than $\alpha(0.05)$.

Table 6: Homogeneity Test of Gain Score

\begin{tabular}{|c|c|c|c|}
\hline Levene Statistic & df1 & df2 & Sig. \\
\hline, 438 & 1 & 39 &, 512 \\
\hline
\end{tabular}

The data is homogeneous if $p$-value is greater than $\alpha(0.05)$ and if $p$-value is equal or lesser than $\alpha(0.05)$, it means data is not homogeneous. Based on the result of the Table 4.6, the result of the data between Diglot Weave and Semantic Mapping were homogeneous because 0.512 is greater than $\alpha(0.05)$. 
Table 7: The Result of Independent Sample T-Test of Normalized Gain

\begin{tabular}{|c|c|c|c|c|c|}
\hline & \multicolumn{2}{|c|}{ Levene's Test } & \multicolumn{3}{|c|}{ t-test } \\
\hline & $\mathrm{F}$ & Sig. & $\mathrm{t}$ & df & $\begin{array}{l}\text { Sig. (2- } \\
\text { tailed) }\end{array}$ \\
\hline $\begin{array}{l}\text { Equal variances } \\
\text { assumed }\end{array}$ & ,438 &, 512 & 6,136 & 39 &, 000 \\
\hline $\begin{array}{l}\text { Equal variances not } \\
\text { assumed }\end{array}$ & & & 6,165 & 38,294 & ,000 \\
\hline
\end{tabular}

Since the population variances of the normalized gain score were homogeneous, the row of equal variances assumed is used. The result showed that the $\mathrm{p}$-value of the gain score is 0.000 which is lesser than $\alpha(0.05)$, so it can be concluded that $\mathrm{H}_{0}$ is rejected. Thus, there is significant difference in enhancing students' vocabulary knowledge between those who were taught by Semantic Mapping and those who were taught by Diglot Weave Techniques. It can be seen from the gain score of both techniques which shows significant difference.

\section{Students Response toward the Techniques}

It is essential to find out the mean of students' response as they were treated to enhance their vocabulary knowledge. The researcher distributed a questionnaire that they should filled out in order to find out their response. The following is result of students' response towards the treatment they received:

Table 8: Students' responses

\begin{tabular}{|c|c|c|}
\hline & SM & DWT \\
\hline Mean of the questionnaire & $\mathbf{8 3 \%}$ & $\mathbf{8 8 \%}$ \\
\hline
\end{tabular}

Based on the data analysis, the mean response of Diglot Weave is $88 \%$ and mean response of Semantic Mapping Technique is 83\%; which means that both techniques fall into 'good' category. The students considered that the treatment they received is good to enhance their vocabulary knowledge.

\section{Conclusion and Suggestion}

In this study, the researcher compared Semantic Mapping and Diglot Weave Techniques to enhance students' vocabulary knowledge. This study was done at SMA Perguruan Advent I Jakarta where the total respondents were 41 students. They were divided into two groups; both groups were given the same vocabulary test and same topics.

This study used quantitative research method with comparative design. In this design, the two classes were given pre-test before being given treatment. After they were treated with the techniques, the post-test was given to find out students' the enhancement on students' vocabulary knowledge. In the pre-test and post-test, both groups got the same pre-test and 
post-test. The vocabulary test consisted of 50 multiple choices questions which were done in 60 minutes.

The collected data from the two groups were calculated then the results showed that Semantic Mapping group's mean of pre-test was 69.5 and the mean of the post-test was 77 . The total gain score was 0.245. Meanwhile the Diglot Weave group's mean of the pre-test was 68.19 and the mean of the post-test was 82.19 the total gain was 0.44 . From this result, it can be seen that both of the groups enhanced in gain score after being given the treatment. However, both techniques can be considered to be effective in enhancing students' vocabulary knowledge. Furthermore, both groups claimed that the treatment they received was good in enhancing their vocabulary knowledge.

Based on research findings, the researcher wants to give some suggestions as follows: a) For Future Researchers, it is hoped that the result of this study can be used as additional reference for future researcher if the future researchers who want to do a similar research in the future in a different context or developing teaching vocabulary; b) for English Teacher, these methods are recommended to be used in enhancing students vocabulary knowledge. 


\section{REFERENCES}

Alfaki, I. M., Vocabulary Input In English Language Teaching: Assessing the Vocabulary Load in Spine Five. 2015.

Alqahtani, M. (2015). The Importance of Vocabulary in Language Learning and How to be taught. International Institute of social and economic sciences. 3(3). 21-34.

Altay, M. (2017). Raising Awareness of Lexical Semantic Relations in Undergraduate EFL Context. Research on Youth and Language. 11 (1). 42-52.

Cook, V. (2001). Using the first language in the classroom. Retrieved in 2003.

Hasan, K. Md. \& Shabdin, A. (2016) PSAA. Conceptualization of Depth of Vocabulary Knowledge with Academic Reading Comprehension. Vol. 51.

Heimlich, J. E., \& Pittelman, S. V. (1986). Semantic Mapping: Classroom Applications. Newark, DE

Kasim, U. \& Wahyuni S. (2016). Implementation of the Semantic Mapping Strategy for Teaching reading Comprehension.

Katemba, C., V. ; Sitompul, N., A., 2018 A Comparison of Using Diglot Weave Technique and Student Team Achievement Division on Student Vocabulary Achievement. Catalyst .

Apr2018, Vol. 17, p29-36. 8p. Retrieved from: https://apiumy.sharepoint.com/personal/sarra_apiu_edu/_layouts/15/onedrive.aspx ?id=\%2Fpersonal\%2F sarra_apiu_edu\%2FDocuments\%2FPublications\%2FCatalyst $\% 2 \mathrm{~F} 2018 \% 2 \mathrm{Fapril}-$

articles\%2F3\%2E\%20A\%20Comparison\%20of\%20Using\%20Diglot $\% 20$ Weave $\% 20$ Techniq ue\%20and\%20Student $\% 20$ Team $\% 20$ Achievement $\% 20$ Division $\% 20$ on $\% 20$ Student $\% 20$ Voca bulary\%20Achievement $\% 2$ Epdf\&parent $=\% 2$ Fpersonal $\% 2$ Fsarra_apiu_edu $\% 2$ FDocuments $\%$ 2FPublications \%2FCatalyst \%2F $2018 \% 2$ Fapril-articles https://web.a.ebscohost.com/abstract?direct=true \&profile=ehost \&scope $=$ site $\&$ authtype $=$ craw ler\&jrnl=19056931\&AN=129783039\&h=WIHPsYuHNBTw94H1d6u7Jk\%2b21WiARB6\%2 bYCILXNBuM8t4NOh17o8Ju1I\%2bgz\%2bZJhLhlUZtSWHonnv2stbxVow1QQ\%3d\%3d\&c

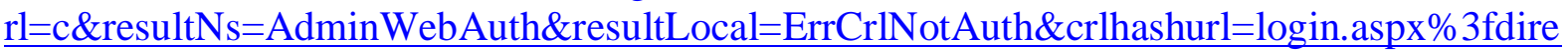
ct $\% 3$ dtrue $\% 26$ profile $\% 3$ dehost $\% 26$ scope $\% 3$ dsite $\% 26$ authtype $\% 3$ dcrawler $\% 26$ jrnl $\% 3 \mathrm{~d} 19056$ $\underline{\text { 931\%26AN\%3d129783039 }}$

Kholi, R., \& Sharififar, S. (2013). Memorization versus Semantic Mapping in L2 Vocabulary Acquisition. ELT Journal: English Language Teachers Journal, 67(2), 199-209.

Karakoça, D. \& Köseb, G. (2017). The impact of vocabulary knowledge on reading, writing and proficiency scores of EFL learners. Journal of Language and Linguistics Studies. 13(1). 352-378.

Lin, C. (2008). Learning German Vocabulary: An Investigation into Learners "Use of Vocabulary Learning Strategies. 
Lynch, R. P. \& Papas, E. (2017). A model for teaching large classes: facilitating a small class fell. International Journal of Higher Education. Vol.6. No. 2. 199-210

Nemati, A. \& Maleki, E. (2013). The Effect of Teaching Vocabulary through the DiglotWeave Technique and Attitude towards This Technique.

Nilforoushan, S., (2012) The Effect of Teaching Vocabulary through Semantic Mapping on EFL Learners' Awareness of the Affective Dimensions of Deep Vocabulary Knowledge. English Language Teaching; Vol. 5, No. 10. 164-172.

Puspita, I. T. (2015). The Effectiveness of Using Semantic Mapping Strategy to Teach Reading Analytical Exposition Texts to the Eleventh Graders of Cendekia Senior High School Sidoarjo.

Rohmatillah, (2014). A study on students' difficulties in learning vocabulary. English Education. Vol. 6 (1). 69-86.

Zarei, A. A., \& Adami, S. (2013). The effects of semantic mapping, thematic clustering, and notebook keeping on L2 vocabulary recognition and production. Journal of English Language Teaching. 3 (2). 17-27 